\title{
Rapid Screening of Drug-Protein Binding Using High-Performance Affinity Chromatography with Columns Containing Immobilized Human Serum Albumin
}

\author{
Ying-Fei Li, ${ }^{1}$ Xiao-Qiong Zhang, ${ }^{1,2}$ Wei-Yu Hu, ${ }^{3}$ Zheng Li, ${ }^{1}$ \\ Ping-Xia Liu, ${ }^{1,4}$ and Zhen-Qing Zhang ${ }^{1}$ \\ ${ }^{1}$ Beijing Institute of Pharmacology and Toxicology, Beijing 100850, China \\ ${ }^{2}$ Institute of Pharmacy, Medical School of Xiang Ya, Central South University, Changsha 410013, China \\ ${ }^{3}$ Hepatobiliary Surgery Department, The Affiliated Hospital of Medical College, Qingdao University, Qingdao 266003, China \\ ${ }^{4}$ Department of Pharmacy, Lushan Sanitarium of PLA, Jiujiang 332000, China
}

Correspondence should be addressed to Zhen-Qing Zhang; zqzhang55@yahoo.com

Received 25 January 2013; Accepted 28 February 2013

Academic Editor: Shuang-Qing Zhang

Copyright ( 2013 Ying-Fei Li et al. This is an open access article distributed under the Creative Commons Attribution License, which permits unrestricted use, distribution, and reproduction in any medium, provided the original work is properly cited.

\begin{abstract}
For drug candidates, a plasma protein binding (PPB) more than $90 \%$ is more meaningful and deserves further investigation in development. In the study, a high-performance liquid chromatography method employing column containing immobilized human serum albumin (HSA) to screen in vitro PPB of leading compounds was established and successfully applied to tested compounds. Good correlation (a coefficient correlation of 0.96 ) was attained between the reciprocal values $(X)$ of experimentally obtained retention time of reference compounds eluted through HSA column and the reported PPB values $(Y)$ with a correlation equation of $Y=92.03-97.01 X$. The method was successfully applied to six test compounds, and the result was confirmed by the conventional ultrafiltration technique, and both yielded equal results. However, due to the particular protein immobilized to column, the method cannot be applied for all compounds and should be exploited judiciously based on the value of the logarithmic measure of the acid dissociation constant ( $\mathrm{pKa}$ ) as per the requirement. If $\alpha 1$-acid glycoprotein and other plasma proteins could be immobilized like HSA with their actual ratio in plasma to column simultaneously, the result attained using immobilized column may be more accurate, and the method could be applied to more compounds without $\mathrm{pKa}$ limitation.
\end{abstract}

\section{Introduction}

When entering into plasma, most compounds bind rapidly to blood constituents. While the phenomenon of plasma protein binding (PPB) of a chemical is considered, it usually means the protein binding of drug molecules to blood components, such as albumin and $\alpha 1$-acid glycoprotein [1]. The concentration of a free drug is primarily responsible for its pharmacological activity, safety, and tissue distribution. The extent of protein binding in plasma is, therefore, considered one of the important physiological factors affecting pharmacokinetic characteristics, such as clearance, volume of distribution, half-life, drug-drug interaction, and the pharmacological efficacy of a drug [2-6].
Conventionally, during the lead characterization stage, protein binding is investigated in rat, dog, monkey, and human plasma. these in vitro studies will help to characterize the therapeutic index for the selection of dose range in clinical trials. However, over the past decade, with the rapid rise in new molecular entities (NMEs) arising from computational lead discovery or modification of natural products, combinatorial chemistry, and high-throughput biological screening, an urgent need has arisen for the determination of the absorption, disposition, metabolism, and excretion properties of these NMEs or even "hit" at earlier stages in the drug discovery pipeline to speed up the selection of "ideal" drug candidates for further development. Back integration of key studies into the discovery phase enables earlier identification 
of potential drug metabolites/pharmacokinetics and safety liabilities [7]. This information increases the effectiveness of discovery scientists in lead selection, optimization, and enhancement of discovery biology and in many instances has been incorporated into criteria for compound advancement into the development phase $[8,9]$. As one of important pharmacokinetic parameters, PPB of lead compounds should be screened at earlier stage.

There are several in vitro methods for measuring the unbound drug concentration in plasma, including equilibrium dialysis, ultrafiltration, gel filtration, and albumin column [10]. Among them, equilibrium dialysis and ultrafiltration are the two most commonly used for determining the unbound drug concentrations in plasma or serum. However, given the need for earlier and more rapid evaluation of a larger number of lead compounds, it is necessary to establish a faster, higher-throughput, and less compound amount consuming approach to screen compound protein binding.

Compared with the conventional methods, chromatography-based methods employing columns immobilized with plasma proteins have been more and more popular over the years for the simplicity, specificity, and speed. Although plasma contains $>60$ different soluble proteins, among these, the major proteins that bind drug are albumin, the richest protein in plasma, and $\alpha 1$-acid glycoprotein. The work in the area of immobilized HSA chromatography was initiated from Noctor and Wainer [11]. Henceforth, various strategies used to investigate the drug-protein interactions for the development of columns immobilized with HSA, including frontal analysis (frontal affinity chromatography), zonal elution, equilibrium dialysis combined with high-performance liquid chromatography (HPLC), and micellar liquid chromatography, have been reported [12-19]. However, all methods could not estimate the PPB of compounds accurately due to compounds binding to other proteins of plasma, in this way the PPB of compounds was often underestimated. Hence, that underestimation, the PPB of compounds was usually attained.

Being a quick means of in vitro PPB estimation based on human serum albumin-HPLC (HSA-HPLC), the method especially suits rapid screening of PPB for numerous leading compounds in early drug discovery phase. The present investigation reports an HSA-based HPLC method for drugprotein binding rapid screening of UV active compounds. An application of the method to six test compounds, was made and the results confirmed by ultrafiltration have also been applied.

\section{Experimental}

2.1. Chemicals and Reagents. A set of commercially available reference compounds with a wide range of $\mathrm{pKa}$ was selected for this study. Caffeic acid, caffeine, catechuic acid, chlorphenamine maleate, chuanxiongzine hydrochloride, clomifene citrate, diazepam, diphenhydramine hydrochloride, ferulic acid, fluconazole, hydrocortisone acetate, nefopam hydrochloride, ranitidine hydrochloride, phenacetin, phenytoin sodium, praziquantel, propranolol hydrochloride, progesterone, reserpine, rutoside, salicylic acid, sulfadiazine, quercetin, sulfadimidine, sulfamethoxazole, testosterone propionate, tolbutamide, vanillic acid, and warfarin sodium with purity of more than $98.6 \%$ (except rutin $(92.5 \%)$ and warfarin sodium (92.6\%)) were all supplied by the National Institutes for Food and Drug Control (Beijing, China). Compounds A, B, C, D, E, and F (Figure 1), with purity of more than $99 \%$, were test compounds which experienced nonclinical pharmacokinetics evaluation as a new drug in our lab. A, B, and D were semisynthetic natural compounds.

Sodium chloride of analytical grade was purchased from Beijing Chemical Works (Beijing, China). HPLC grade methanol (USA) and acetonitrile (Trinidad) were purchased from Fisher Scientific Inc., and the other chemicals used were all of analytical reagent grade. HPLC grade water was prepared with a Direct-Q 3 UV water purifying system (Millipore, Bedford, MA, USA).

All solutions were kept in the refrigerator at $4^{\circ} \mathrm{C}$. The solutions were filtrated through $0.22 \mu \mathrm{m}$ membrane (Millipore) before injection.

2.2. Instruments. The assay was performed on an Agilent 1100 series HPLC system (Agilent Technologies, Waldbronn, Germany) consisting of a quaternary pump, an autosampler, a vacuum degasser, and a UV absorbance detector set at $210 \mathrm{~nm}$.

\subsection{Chromatographic Methods for Drug-Protein Binding} Screening Using Immobilized HSA Columns. Compounds were dissolved with water or water-ethanol (with different ratio) to a concentration of $100 \mu \mathrm{g} / \mathrm{mL}$. The chromatographic peak was attained on a $5 \mu \mathrm{m}$ Chiral-HSA, $50 \times 3 \mathrm{~mm}$ column (Chrom Tech, France), which was preceded by an on-line filter. The ChemStation for LC 3D software was used for data acquiring and handling. As a generic rapid method, an isocratic mobile phase was selected. To simulate physiology environment, a mobile phase consisting of $0.9 \% \mathrm{NaCl}(\mathrm{pH}$ 7.0) at a flow rate of $0.5 \mathrm{~mL} / \mathrm{min}$ was used. $10 \mu \mathrm{L}$ aliquot of analyte solution was injected to HPLC to be analyzed.

\subsection{PPB Experiment for Test Compounds by Ultrafiltration.} The stock solution ( 1.0 or $2 \mathrm{mg} / \mathrm{mL}$ ) of test compounds was prepared by dissolving appropriate amount of compounds in water-methanol $(50: 50, \mathrm{v} / \mathrm{v})$ mixture. Working solution (1, 10 or $100 \mu \mathrm{g} / \mathrm{mL}$ ) was attained by diluted stock solution with water. A different volume of the working solution was added to a $2 \mathrm{~mL}$ eppendorf vial and evaporated to dryness under a stream of nitrogen in the thermostatically controlled water bath maintained at $55^{\circ} \mathrm{C}$ for about $20 \mathrm{~min}$. Drug-free plasma $(0.5 \mathrm{~mL})$ was then added to it and vortexed for $5 \mathrm{~min}$ to get the final concentration of $10,40,200,100,2000$, and $100 \mathrm{ng} / \mathrm{mL}$ for compounds A, B, C, D, E, and F, respectively. The mixture was incubated at $37^{\circ} \mathrm{C}$ for $30 \mathrm{~min}$. Thereafter, $400 \mu \mathrm{L}$ aliquot of the sample was loaded into the preheated sample reservoir of Microcon YM-30 filter device (filter pore size $30 \mathrm{kDa}$ ) and centrifuged for $45 \mathrm{~min}$ at $5000 \mathrm{~g}$ and $37^{\circ} \mathrm{C}$. The filtrate was analyzed for the drug content by HPLC-MS.

To estimate the nonspecific binding of the test drugs to the filter membrane, $500 \mu \mathrm{L}$ of the solution of each compound 
<smiles>CCN(CC)Cc1cc(-c2nc3c(Cl)nnc(OC)c3n2C)ccc1O</smiles><smiles>CC(=O)N[C@@H](Cc1ccc2ccccc2c1)C(=O)N[C@@H](Cc1ccc(Cl)cc1)C(=O)N[C@@H](Cc1ccccc1)C(=O)N[C@@H](CO)C(=O)N[C@@H](CCCNC(=N)N)C(=O)N[C@@H](Cc1cccnc1)C(=O)N[C@@H](CC(C)C)C(=O)NC(CCCNC(=N)N)C(=O)N1CCC[C@H]1C(=O)N[C@@H](C)C(N)=O</smiles>

Figure 1: Chemical structures of six test compounds.

tested was centrifuged for $45 \mathrm{~min}$ at $5000 \mathrm{~g}$ in a Microcon YM-30 filter device. The concentration of the filtrate was analyzed by HPLC-MS. The nonspecific binding was $<5 \%$ for each compound. The PPB by ultrafiltration was performed in triplicates for all the compounds studied.

2.5. $p K a$ Calculation and Correlation Analysis. The $\mathrm{pKa}$ for all compounds except progesterone was calculated using ACD/labs 6.0. The pKa of progesterone was calculated by Pallas. Origin 6.0 was used to perform the plot and statistical analysis of the linear regressions.

\section{Results and Discussion}

Around 30 different compounds with PPB ranging from 11.5 to $98.0 \%$ were analyzed using immobilized HSA-HPLC. Most compounds with low PPB eluted at a lower retention time and exhibited sharp peak shapes as compared with the high protein bound compounds. Representative chromatograms are shown in Figure 2. There is one compound, clomifene citrate, that did not elute from HSA column to 240 min due to the strong binding. The related information about the reference compounds was listed in Table 1.
Every compound binds to all the plasma proteins to a certain extent. Hence that for the data of all reference compounds, there is no manifest relationship between retention time (RT) and reported PPB of compounds as showed in Figure 3. Because albumin generally binds acidic drugs better while $\alpha 1$-acid glycoprotein preferentially binds to basic drugs $[1,6]$, pKa less than 7.0 was used as a criterion for the drug binding to HSA mainly. However, for numerous leading compounds, it is difficult to know their actual pKa values. So the pKa values (Table 1) for drugs were predicted by ACD/Labs, one of the most accurate softwares to predict the pKa as reported [20]. Obviously, there is a hyperbola relationship for compounds with pKa less than 7.0 which mainly binds to HSA. A good linear correlation was attained between the reciprocal value of retention time and the reported PPB with a correlation equation of $Y=92.03-97.01 X$ and coefficient correlation of 0.96 using linear regression fit of Origin 6.0 (Figure 4).

Some understanding of the possible binding characteristics of candidate molecules could supply valuable information in the strategies of the design process, so the linear relationship established above was used to rapidly predict the protein binding. An interaction is likely, and a clinical study should be performed to quantify the effects if the drug of interest has 

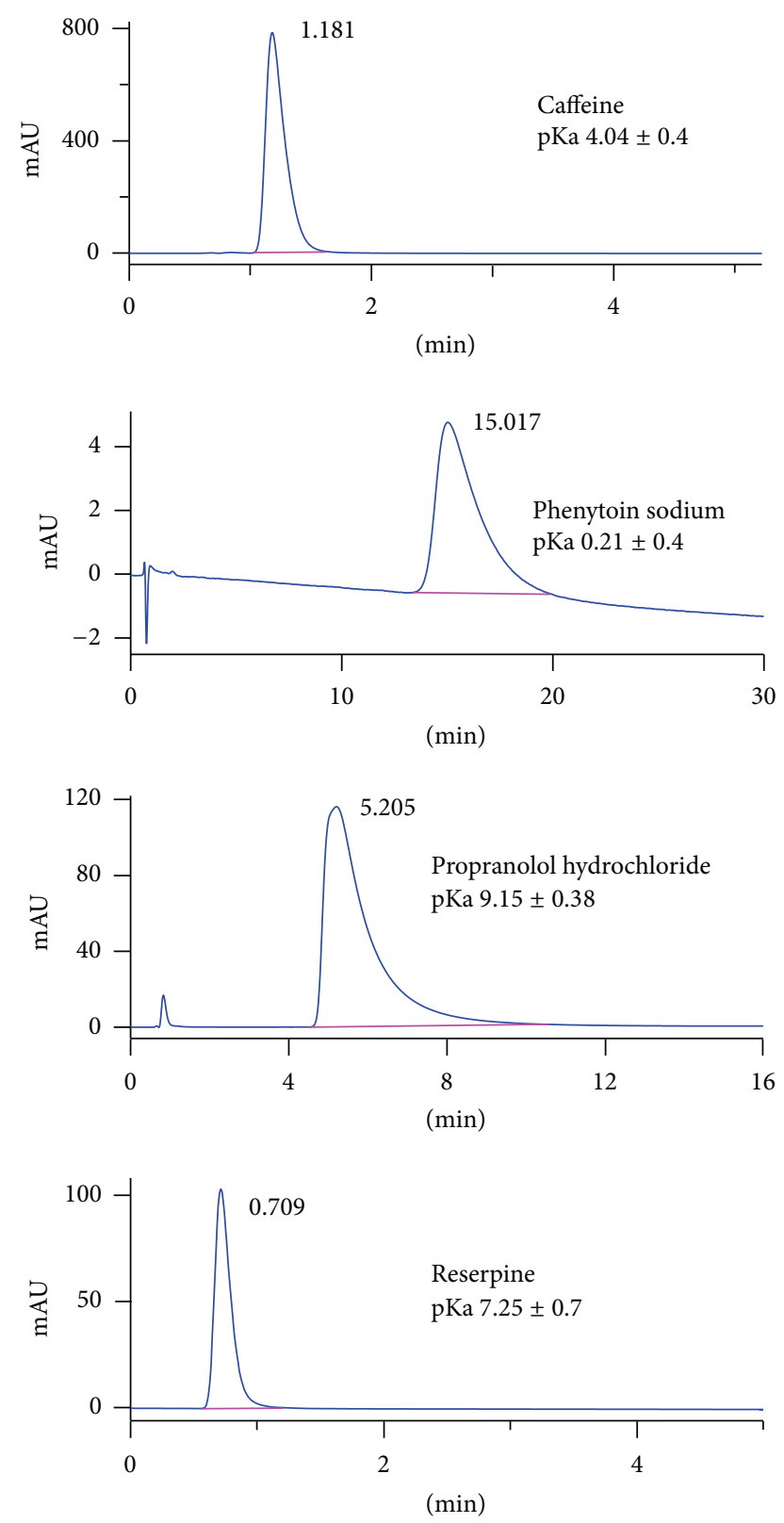

FIGURE 2: Representative chromatograms of some reference compounds analysed on HSA column.

a PPB above 90\%, and narrow therapeutic index, high hepatic extraction ratio, and especially intravenous administration will increase the possibility [21]. For leading compounds, $\mathrm{PPB}$ of $90 \%$ is an appropriate index to decide whether the $\mathrm{PPB}$ of a drug needs to be investigated using the method of equilibrium dialysis or ultrafiltration in the following development phase.

Based on the upper prediction limit with 95\% confidence interval, the reciprocal value of retention time for the compound in the HSA column should be less than 0.22 when its protein binding was more than $90 \%$ (Figure 4 ). This means that the retention time of the drug was more than $4.55 \mathrm{~min}$ in the HSA column if its PPB was more than $90 \%$. Although the $\mathrm{pKa}$ of diphenhydramine hydrochloride, rutoside, nefopam

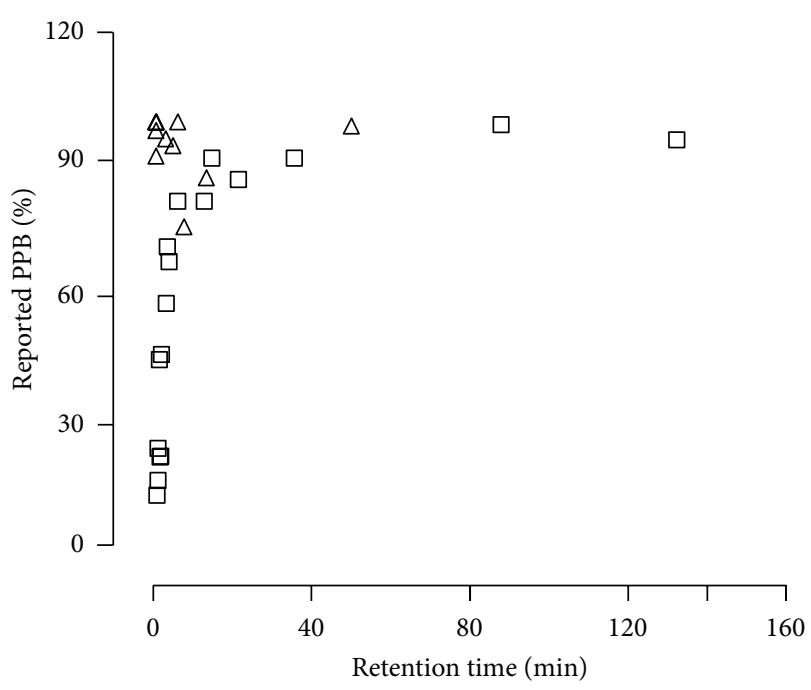

FIGURE 3: Scatter plot of retention time of reference compounds using immobilized HAS-HPLC and the corresponding reported $\mathrm{PPB}$ values. $\triangle$ : compounds with $\mathrm{pKa}<7.0$; $\square$ : compounds with $\mathrm{pKa}>7.0$.

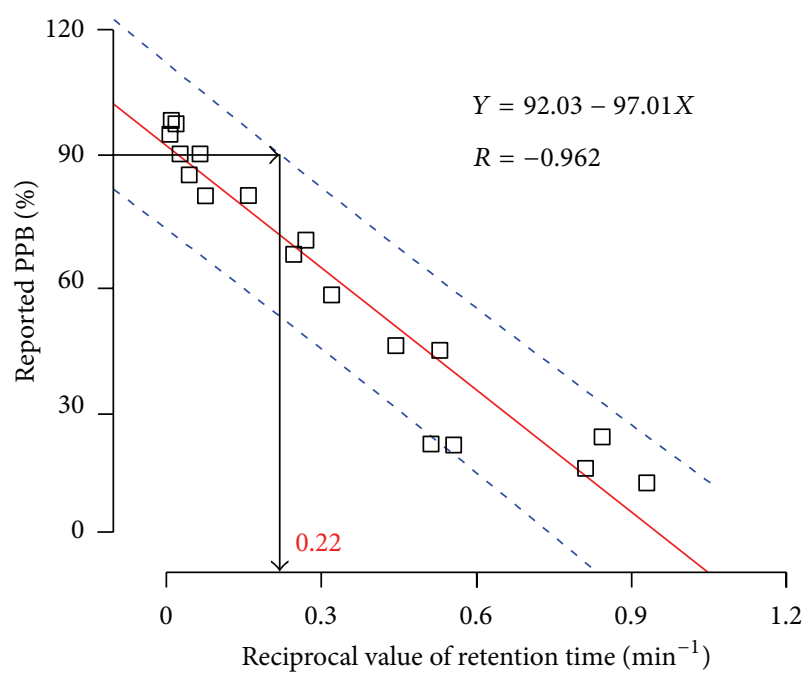

FIGURE 4: Correlation between reciprocal values of retention time of reference compounds ( $\mathrm{pKa}<7.0$ ) by immobilized HAS-HPLC and the reported PPB values. The solid line was linear ship achieved by Origin 6.0 linear regression fit. The dash line represents $95 \%$ prediction limits.

hydrochloride, progesterone, and propranolol hydrochloride is $8.76,13.85,9.16,15.00$, and 9.15, respectively, far more than 7.0 , the retention time of the drugs in the HSA column was $6.23,13.43,7.87,50.02$, and $5.21 \mathrm{~min}$, respectively, later than $4.50 \mathrm{~min}$. The reported $\mathrm{PPB}$ of diphenhydramine hydrochloride, progesterone, and propranolol hydrochloride is $98 \%, 97 \%$, and $90-95 \%$, respectively. And the value for rutoside and nefopam was $80-90 \%$ and $71-76 \%$ close to $90 \%$. Therefore, the compounds with retention time in the HSA column later than 4.55 min were potentially more than $90 \%$ regardless of the $\mathrm{pKa}$ value and need the further investigation. 
TABLE 1: The retention time, reported PPB, and predicted pKa of reference compounds.

\begin{tabular}{|c|c|c|c|}
\hline Compound & Retention time (min) & PPB from literature (\%) & pKa based on ACD/labs \\
\hline Caffeic acid & 4.02 & 66.0 & $4.04 \pm 0.40$ \\
\hline Caffeine & 1.18 & 22.5 & $0.63 \pm 0.70$ \\
\hline Catechuic acid & 1.94 & 20.7 & $4.45 \pm 0.10$ \\
\hline Chlorphenamine maleate & 5.93 & $37.5(25-50)$ & $3.77 \pm 0.19$ \\
\hline Chuanxiongzine hydrochloride & 2.23 & 44.3 & $2.88 \pm 0.50$ \\
\hline Diazepam & 132.21 & $94.5(90-99)$ & $3.40 \pm 0.10$ \\
\hline Ferulic acid & 1.79 & 20.6 & $4.04 \pm 0.40$ \\
\hline Fluconazole & 1.07 & $11.5(11-12)$ & $2.56 \pm 0.12$ \\
\hline Ranitidine hydrochloride & 1.23 & $15.0(12-18)$ & $2.38 \pm 0.70$ \\
\hline Phenytoin sodium & 15.02 & 90.0 & $0.21 \pm 0.40$ \\
\hline Praziquantel & 12.97 & 80.0 & $-0.79 \pm 0.20$ \\
\hline Salicylic acid & 21.81 & $85.0(80-90)$ & $3.01 \pm 0.10$ \\
\hline Sulfadiazine & 1.88 & $43.0(38-48)$ & $1.57 \pm 0.10$ \\
\hline Sulfadimidine & 6.22 & 80.0 & $1.55 \pm 0.10$ \\
\hline Sulfamethoxazole & 3.68 & $69.5(69-70)$ & $1.39 \pm 0.10$ \\
\hline Tolbutamide & 35.82 & 90.0 & $5.12 \pm 0.50$ \\
\hline Vanillic acid & 3.11 & 56.3 & $4.45 \pm 0.10$ \\
\hline Warfarin & 87.85 & 98.0 & $4.50 \pm 1.00$ \\
\hline Bendroflumethiazide & 3.27 & 94.0 & $8.63 \pm 0.40$ \\
\hline Diphenhydramine hydrochloride & 6.23 & 98.0 & $8.76 \pm 0.28$ \\
\hline Hydrocortisone acetate & 0.73 & 90.0 & $13.46 \pm 0.70$ \\
\hline Rutoside & 13.43 & $85.0(80-90)$ & $13.85 \pm 0.70$ \\
\hline Nefopam hydrochloride & 7.87 & $73.5(71-76)$ & $9.16 \pm 0.70$ \\
\hline Phenacetin & 3.19 & 30.0 & $14.57 \pm 0.70$ \\
\hline Progesterone & 50.02 & 97.0 & $19.28^{*}$ \\
\hline Propranolol hydrochloride & 5.21 & $92.5(90-95)$ & $9.15 \pm 0.38$ \\
\hline Quercetin & 0.72 & 98.0 & $8.14 \pm 0.60$ \\
\hline Reserpine & 0.71 & 96.0 & $7.25 \pm 0.70$ \\
\hline Testosterone propionate & 0.74 & 98.0 & $9.63 \pm 0.65$ \\
\hline
\end{tabular}

${ }^{*}$ Calculated by software of Pallas.

TABLE 2: Retention time, predicted pKa, experimental PPB, and result by HSA-HPLC of test compounds

\begin{tabular}{lcccc}
\hline Compound & Retention time (min) & pKa based on ACD/labs & PPB by ultrafiltration (\%) & Screening result by HSA-HPLC (\%) \\
\hline Comp. A & 0.76 & $9.49 \pm 0.12$ & 78.2 & - \\
Comp. B & 1.70 & $14.24 \pm 0.60$ & 21.6 & - \\
Comp. C & 1.75 & $1.17 \pm 0.50$ & 51.0 & $<90$ \\
Comp. D & 4.87 & $9.46 \pm 0.60$ & 95.0 & $>90$ \\
Comp. E & $>5.00$ & $3.17 \pm 0.10$ & 99.5 & $>90$ \\
Comp. F & 0.81 & $15.06 \pm 0.46$ & 97.2 & - \\
\hline
\end{tabular}

-: compound is not appropriate for the method of HSA-HPLC.

The PPB attained by ultrafiltration was $78.2 \pm 1.67 \%$, $21.6 \pm 2.30 \%, 51.0 \pm 2.52 \%, 94.86 \pm 0.56 \%, 99.5 \pm 0.24 \%$, and $97.2 \pm 0.60 \%$ for test compounds $\mathrm{A}, \mathrm{B}, \mathrm{C}, \mathrm{D}, \mathrm{E}$, and F, respectively. The $\mathrm{PPB}$ of six compounds experienced nonclinical evaluation which was rapidly screened (Table 2 ) by the immobilized HSA-HPLC, and a confirmation with the result of the ultrafiltration was made. There were two compounds, $\mathrm{D}$ and $\mathrm{E}$, with retention time more than $4.55 \mathrm{~min}$ which indicated that the PPB of these two compounds was more than $90 \%$. The result of the ultrafiltration confirmed that the PPB was $95.0 \%$ and $99.5 \%$ for compounds D and E, respectively. For the left four compounds, only the pKa of compound $\mathrm{C}$ is less than 7.0 and the retention time of which is $1.75 \mathrm{~min}$ less than $4.55 \mathrm{~min}$. So the PPB of compound C based on the HSA column was less than $90 \%$ and the PPB of compound $\mathrm{C}$ using ultrafiltration was $51.5 \%$. The results were consistent with each other. However, the pKa of compounds A, F, and B was 9.49, 15.06, and 14.24, respectively, which is all 
more than 7.0. Due to binding to other constitutes of blood, the PPB of these drugs couldnot be predicted based on the retention time attained using the method of the HSA column.

Every compound binds to all the plasma proteins to a certain extent. The percentage protein binding obtained by the ultrafiltration method measures all the specific and nonspecific binding to all of the plasma components. Although the HSA-HPLC method measures both the specific and nonspecific binding to one particular protein and cannot reflect the binding to the other plasma proteins, it is still a quick means of in vitro PPB screening for lead compounds. If $\alpha 1$-acid glycoprotein and other plasma proteins could be immobilized like HSA with their actual ratio in plasma to column simultaneously, the result attained using immobilized column may be more accurate, and the method could be applied to more compounds without $\mathrm{pKa}$ limitation. A further validation of the method is under way.

\section{Conclusions}

In accordance with the result of ultrafiltration, the HSAHPLC method described in the present investigation could be applied in rapid screening lead compounds within $5 \mathrm{~min}$ in early drug discovery programs. It can be concluded that HSAHPLC is suitable for the compounds that are designed to specifically or to some extent bind to HSA. The current commercial available HSA columns can be used in drug-protein binding screening while AGP columns are not as appropriate for such work. Further, using more analysis capacity HPLCMS technique instead of HPLC, higher throughput for such studies will be acquired.

\section{Authors' Contribution}

Y.-F. Li and X.-Q. Zhang contributed equally in this work.

\section{Acknowledgment}

The authors thank the financial support from the National Natural Science Foundation of China (Grant no. 81202578) for this work.

\section{References}

[1] Y. Kwon, Handbook of Essential Pharmacokinetics, Pharmacodynamics, and Drug Metabolism For Industrial Scientists, Kluwer Academic/Plenum Publishers, New York, NY, USA, 2001.

[2] S. L. Rodgers, A. M. Davis, N. P. Tomkinson, and H. Van De Waterbeemd, "QSAR modeling using automatically updating correction libraries: application to a human plasma protein binding model," Journal of Chemical Information and Modeling, vol. 47, no. 6, pp. 2401-2407, 2007.

[3] H. van de Waterbeemd, "Which in vitro screens guide the prediction of oral absorption and volume of distribution?" Basic and Clinical Pharmacology and Toxicology, vol. 96, no. 3, pp. 162-166, 2005.

[4] H. van de Waterbeemd, "High-throughput and in silico techniques in drug metabolism and pharmacokinetics," Current
Opinion in Drug Discovery \& Development, vol. 5, no. 1, pp. 3343, 2002.

[5] P. R. Chaturvedi, C. J. Decker, and A. Odinecs, "Prediction of pharmacokinetic properties using experimental approaches during early drug discovery," Current Opinion in Chemical Biology, vol. 5, no. 4, pp. 452-463, 2001.

[6] C. Han, C. B. Davis, and B. Wang, Evaluation of Drug Candidates for Preclinical Development: Pharmacokinetics, Metabolism, Pharmaceutics, and Toxicology, John Wiley \& Sons, Hoboken, NJ, USA, 2010.

[7] E. H. Kerns and L. Di, Drug-Like Properties: Concepts, Structure Design and Methods: From ADME to Toxicity Optimization, Academic Press, Amsterdam, The Netherlands, 2008.

[8] A. F. Nassar, P. F. Hollenberg, and J. Scatina, Drug Metabolism Handbook: Concepts and Applications, Wiley, Hoboken, NJ, USA, 2009.

[9] R. T. Borchardt, Optimizing the, "Drug-Like" Properties of Leads in Drug Discovery, Springer, New York, NY, USA, 2006.

[10] J. Oravcova, B. Bohs, and W. Lindner, "Drug-protein binding studies new trends in analytical and experimental methodology," Journal of Chromatography B, vol. 677, no. 1, pp. 1-28, 1996.

[11] T. A. Noctor and I. W. Wainer, "The in situ acetylation of an immobilized human serum albumin chiral stationary phase for high-performance liquid chromatography in the examination of drug-protein binding phenomena," Pharmaceutical Research, vol. 9, no. 4, pp. 480-484, 1992.

[12] P. R. Tiller, I. M. Mutton, S. J. Lane, and C. D. Bevan, "Immobilized human serum albumin: liquid chromatography/mass spectrometry as a method of determining drug-protein binding," Rapid Communications in Mass Spectrometry, vol. 9, no. 4, pp. 261-263, 1995.

[13] Y. C. Guillaume, E. Peyrin, and A. Berthelot, "Chromatographic study of magnesium and calcium binding to immobilized human serum albumin," Journal of Chromatography B, vol. 728, no. 2, pp. 167-174, 1999.

[14] M. C. Millot, S. Servagent-Noinville, N. L. Taleb, M. H. Baron, M. Revault, and B. Sébille, "Structural changes of human serum albumin immobilized on chromatographic supports: a highperformance liquid chromatography and Fourier-transform infrared spectroscopy study," Journal of Chromatography B, vol. 753, no. 1, pp. 101-113, 2001.

[15] Y. Cheng, E. Ho, B. Subramanyam, and J. L. Tseng, "Measurements of drug-protein binding by using immobilized human serum albumin liquid chromatography-mass spectrometry," Journal of Chromatography B, vol. 809, no. 1, pp. 67-73, 2004.

[16] R. Mallik, M. J. Yoo, C. J. Briscoe, and D. S. Hage, "Analysis of drug-protein binding by ultrafast affinity chromatography using immobilized human serum albumin," Journal of Chromatography A, vol. 1217, no. 17, pp. 2796-2803, 2010.

[17] R. Matsuda, J. Anguizola, K. S. Joseph, and D. S. Hage, "Analysis of drug interactions with modified proteins by highperformance affinity chromatography: binding of glibenclamide to normal and glycated human serum albumin," Journal of Chromatography A, vol. 1265, pp. 114-122, 2012.

[18] Z. Tong, K. S. Joseph, and S. D. Hage, "Detection of heterogeneous drug-protein binding by frontal analysis and highperformance affinity chromatography ," Journal of Chromatography $A$, vol. 1218, no. 49, pp. 8915-8924, 2011.

[19] R. Matsuda, J. Anguizola, K. S. Joseph, and D. S. Hage, "Highperformance affinity chromatography and the analysis of drug interactions with modified proteins: binding of gliclazide with 
glycated human serum albumin "' Analytical and Bioanalytical Chemistry, vol. 401, no. 9, pp. 2811-2819, 2011.

[20] Z. Tong, J. E. Schiel, E. Papastavros, C. M. Ohnmacht, Q. R. Smith, and D. S. Hage, "Kinetic studies of drug-protein interactions by using peak profiling and high-performance affinity chromatography: examination of multi-site interactions of drugs with human serum albumin columns," Journal of Chromatography A, vol. 1218, no. 15, pp. 2065-2071, 2011.

[21] C. Bertucci, V. Andrisano, R. Gotti, and V. Cavrini, "Use of an immobilised human serum albumin HPLC column as a probe of drug-protein interactions: the reversible binding of valproate," Journal of Chromatography B, vol. 768, no. 1, pp. 147$155,2002$. 

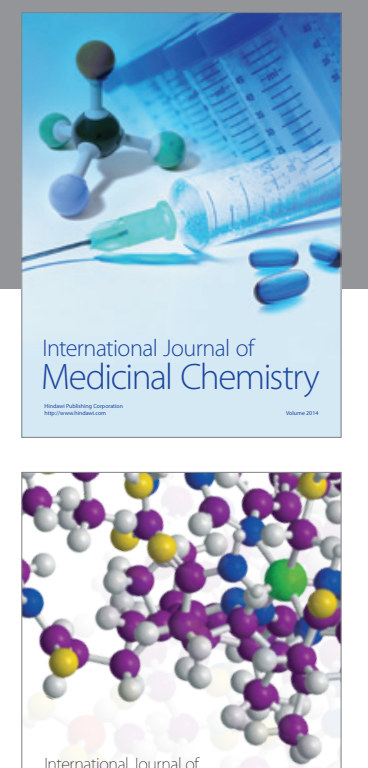

\section{Carbohydrate} Chemistry

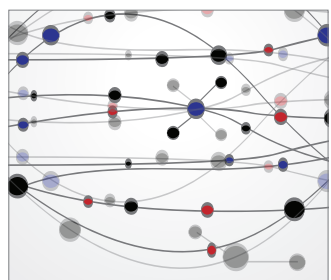

The Scientific World Journal
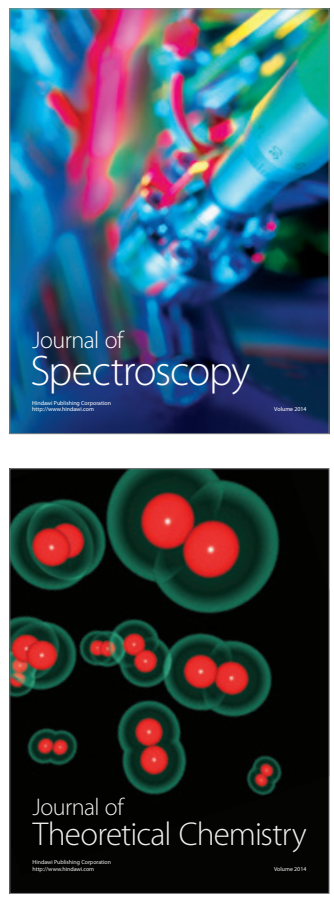
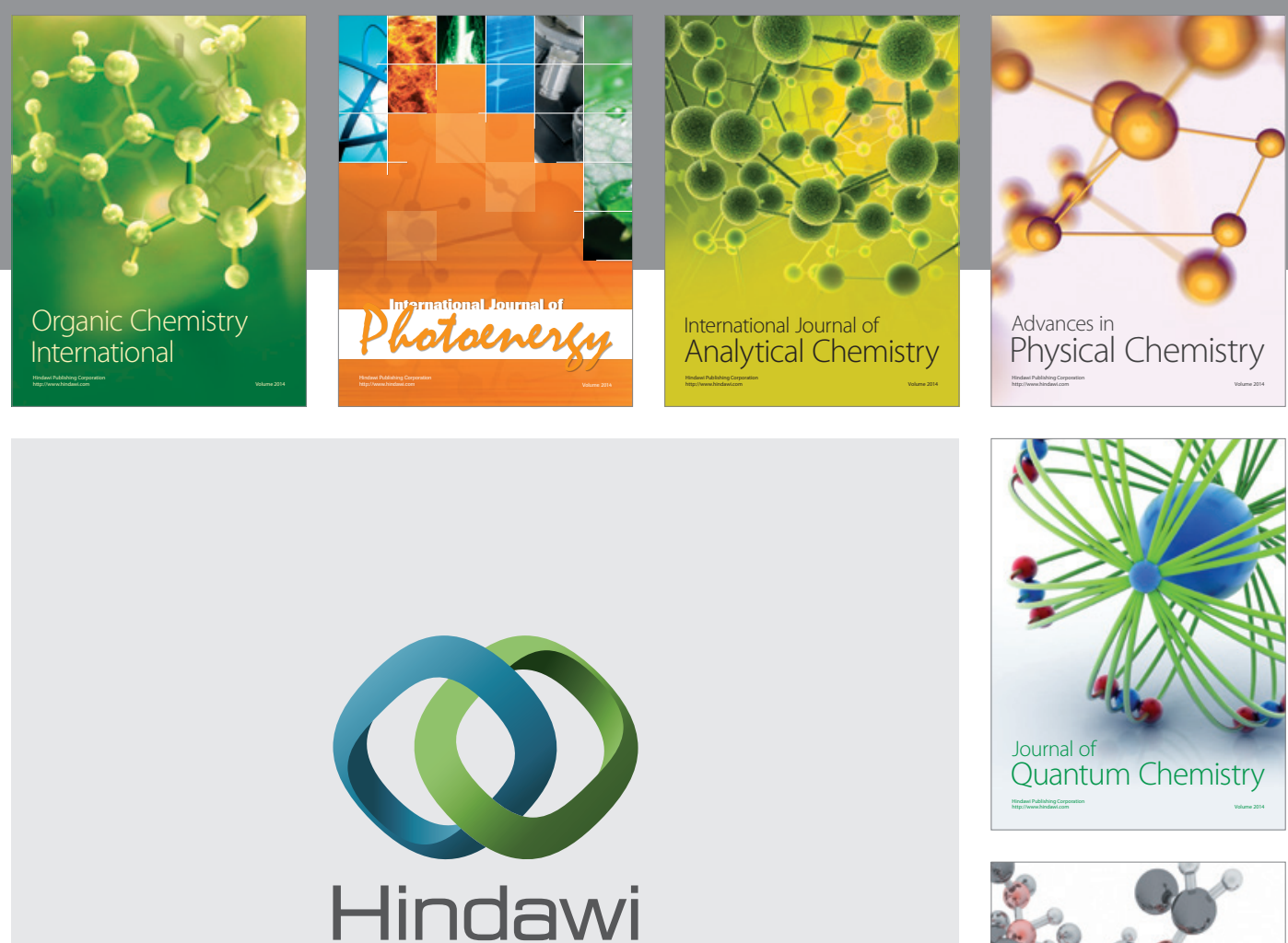

Submit your manuscripts at

http://www.hindawi.com

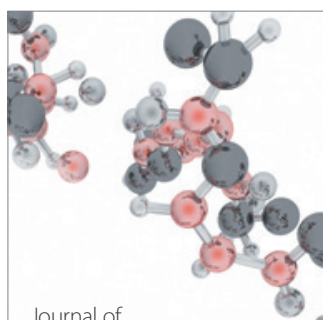

Analytical Methods

in Chemistry

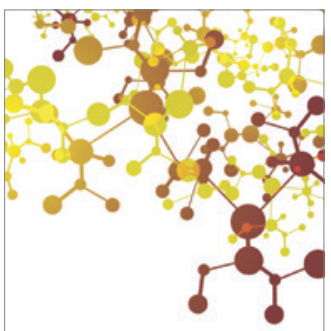

Journal of

Applied Chemistry

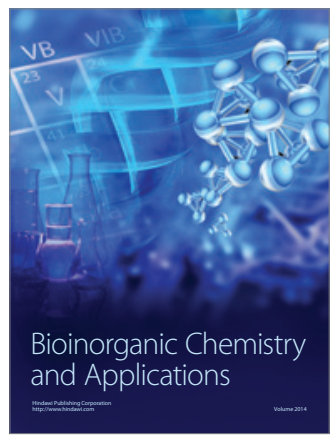

Inorganic Chemistry
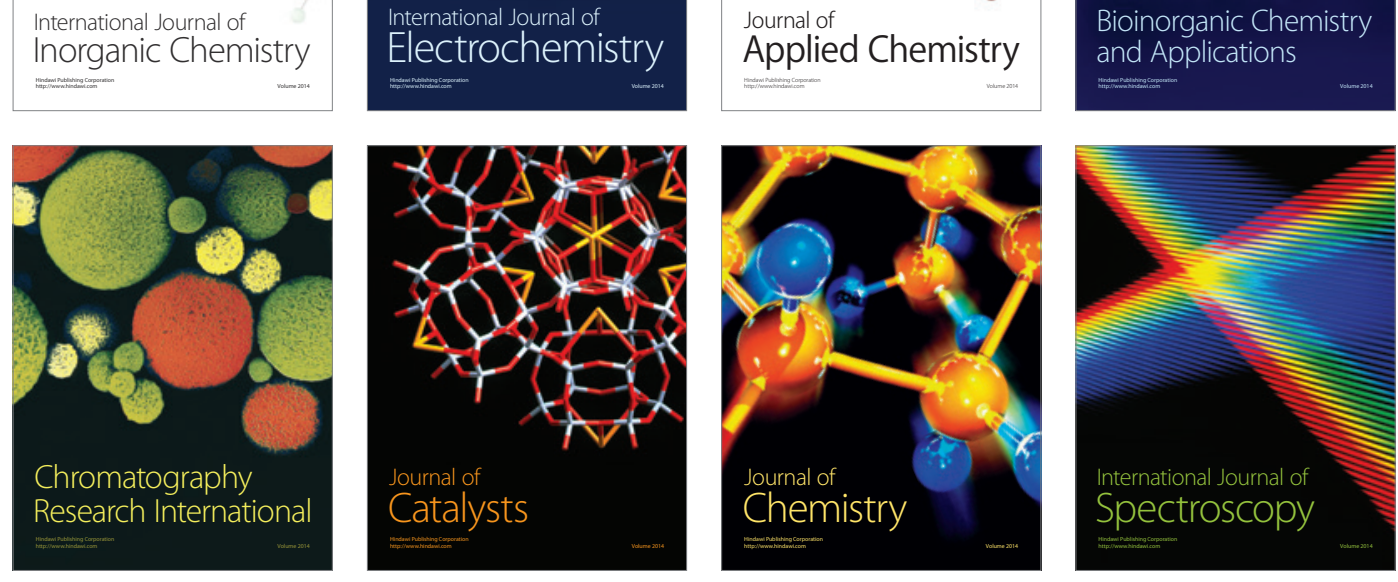